\title{
Marie Curie e Einstein Finalmente na Sede da SPQ
}

Após uma viagem algo atribulada, desde 30 de novembro que finalmente se encontra a decorar as instalações da Sede da Sociedade Portuguesa de Química a peça de artesanato "Einstein com Marie Curie", vencedora do concurso INOVARTE 2011, promovido pela ADERE-Minho com o apoio da SPQ, e dedicado ao tema "Ano Internacional da Química" (tal como noticiado no QUíMICA 122).

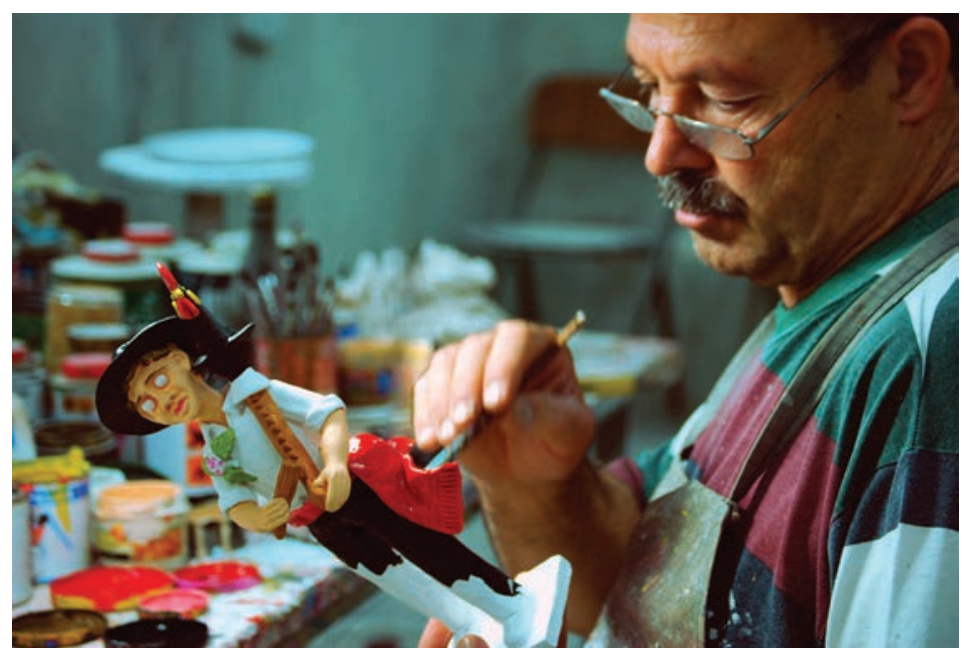

O artesão Manuel Macedo
A peça, com cerca de $50 \mathrm{~cm}$ de altura, é da autoria de Manuel Macedo, artesão natural de Barcelos, uma região minhota onde por tradição se trabalha o barro.

É em Galegos de Sta $^{\text {ta }}$ Maria que Manuel Macedo dá forma e cor às suas criações e onde diz que "tudo começa com um rolo de barro. A partir daí ....". A partir daí aparecem figuras de san- tos, músicos, minhotas e gentes do campo e das profissões. Nestas, na categoria dos cientistas, apareceram Marie Curie e Einstein, que ficarão na sede da SPQ a lembrar que 2011, ano do centésimo aniversário da Sociedade, foi o Ano Internacional da Química.

João Paulo André

(jandre@quimica.uminho.pt) Universidade do Minho

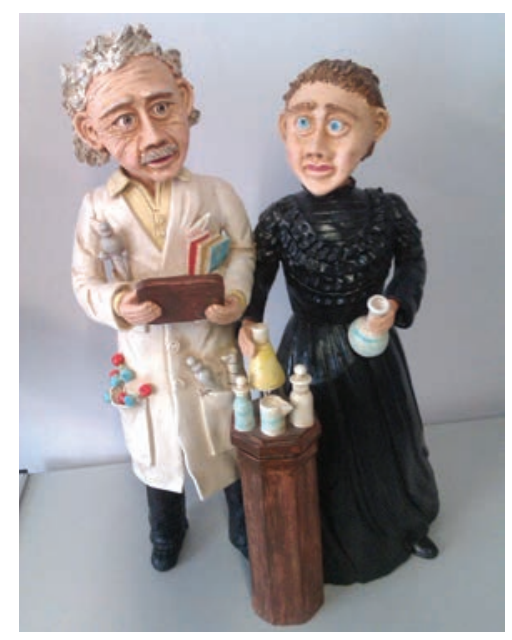

"Einstein com Marie Curie" - amigos em vida e agora juntos na SPQ

\section{Encontro Luso-Galego de Química}

O XVIII Encontro Luso-Galego de Química decorreu de 28 a 30 de novembro de 2012 na Universidade de Trás-os-Montes e Alto Douro, em Vila Real. Participaram mais de 240 investigadores vindos de Portugal e de Espanha, tendo sido apresentados mais de 190 trabalhos de investigação. Os Encontros Luso-Galegos de Química têm por objetivo o intercâmbio científico e tecnológico entre Portugal e a Galiza e têm a particularidade de serem especialmente dedicados aos investigadores mais jovens (estudantes de graduação, pós-graduação e recém-doutorados). Desde o seu início, em 1985, o Encontro tem servido o propósito de estabelecer pontes de contacto entre académicos e industriais, com interesses comuns nos aspetos fundamentais e aplicados da Química. O Encontro, este ano com a organização a cargo do Departa- mento de Química da UTAD, resulta da estreita relação existente entre a Sociedade Portuguesa de Química (SPQ), o Colégio Oficial de Químicos (COLQUIGA) e a Associação dos Químicos da Galiza (AQUIGA).

Ao longo destes três dias debateram-se assuntos relacionados com múltiplos temas das Ciências Químicas, divididos em diferentes áreas: Química Fundamental; Química Industrial e Tecnologia; Química Agro-Mar-Alimentar; Química Ambiental; Bioquímica e Biotecnologia; Nanoquímica e Nanotecnologia; Química e Saúde; Química e Energia; Educação e Ensino da Química.

O Encontro manteve a sua estrutura habitual tendo como ponto de partida 5 lições plenárias convidadas, apresentadas na Aula Magna da UTAD:
- LP 1 - Gianluca Li Puma, Universidade de Loughborough, Inglaterra

Semiconductor photocatalysis and photoreaction engineering for environmental and renewable energy applications

- LP 2 - Juan Mogín del Pozo, Colegio Oficial de Químicos de Galicia

Presente y futuro del papel de la química en el campo de la Gestión de Residuos

- LP 3 - Jorge Calado, Departamento de Engenharia Química, IST, Universidade de Lisboa

\section{A História da Energia}

- LP 4 - Victor Freitas, Departamento de Química, FCUP, Universidade do Porto

Contribuição dos polifenóis para as características sensoriais de vinhos tintos 
- LP 5 - Héctor Rodríguez Martínez, Universidade de Santiago de Compostela

Ionic liquids for better processes

O Encontro, como é já tradicional, subdividiu-se em sessões orais paralelas, com a duração de 10-15 minutos, que decorreram em 3 auditórios em simultâneo (Auditórios 1, 2 e Geociências) e na apresentação de comunicações em forma de painel (distribuídas ao longo dos corredores do $1 .^{\circ}$ andar do edifício da Reitoria e do edifício de Geociências da UTAD). Realizou-se ainda, na tarde do dia 30 de novembro (sexta-feira), um mini-Simpósio dedicado aos Líquidos lónicos, que teve como comunicação final convidada a Keynote de Luis Paulo Rebelo (ITQB) intitulada: Salty Chemistry: Fundamentals, Applications and Case Studies involving Ionic Liquids.

De uma forma complementar, ao longo dos três dias, realizaram-se várias atividades:

- Uma wine party com a prova de diferentes vinhos do Douro (tarde de quarta-feira);

- Um concerto de piano na Aula Magna da UTAD, pelo pianista brasileiro Humberto Luiz (final da tarde de quarta-feira);

- Uma sessão de autógrafos do Prof. Jorge Calado, autor do livro Haja Luz, na manhã de quinta-feira;

- O jantar do Encontro, realizado no Hotel MiraCorgo (Vila Real), na noite de quinta- feira;

- Uma exposição de material, reagentes e equipamentos da área da Química, de diversas empresas,

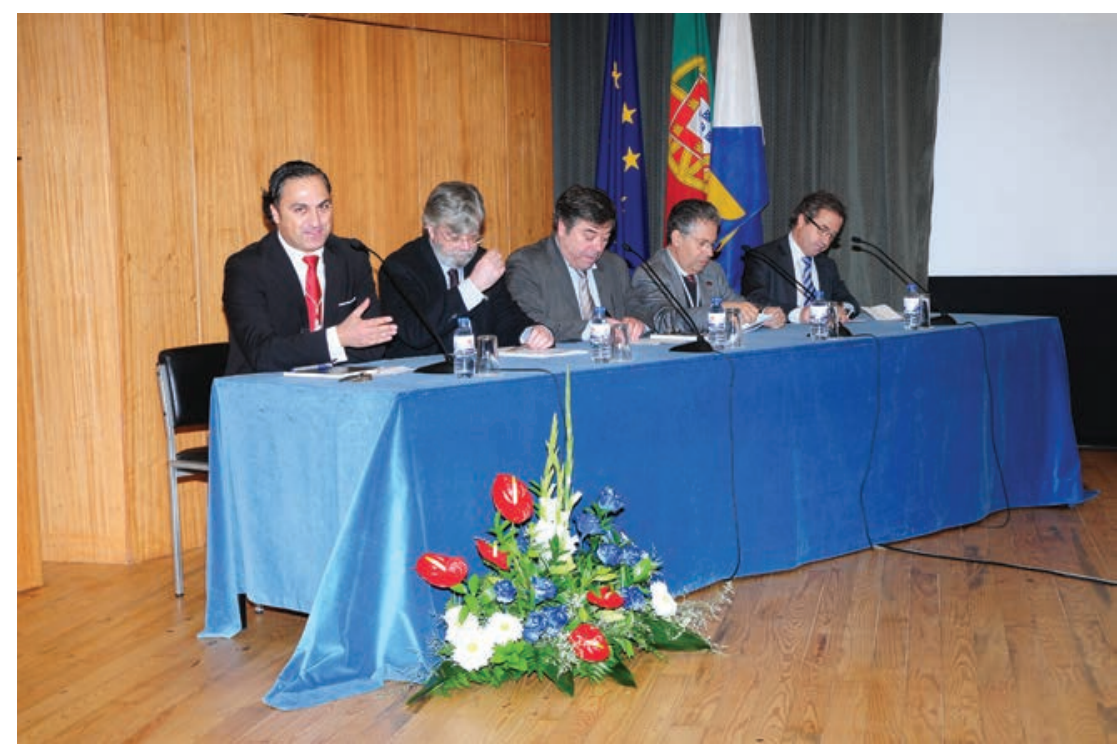

Sessão de abertura

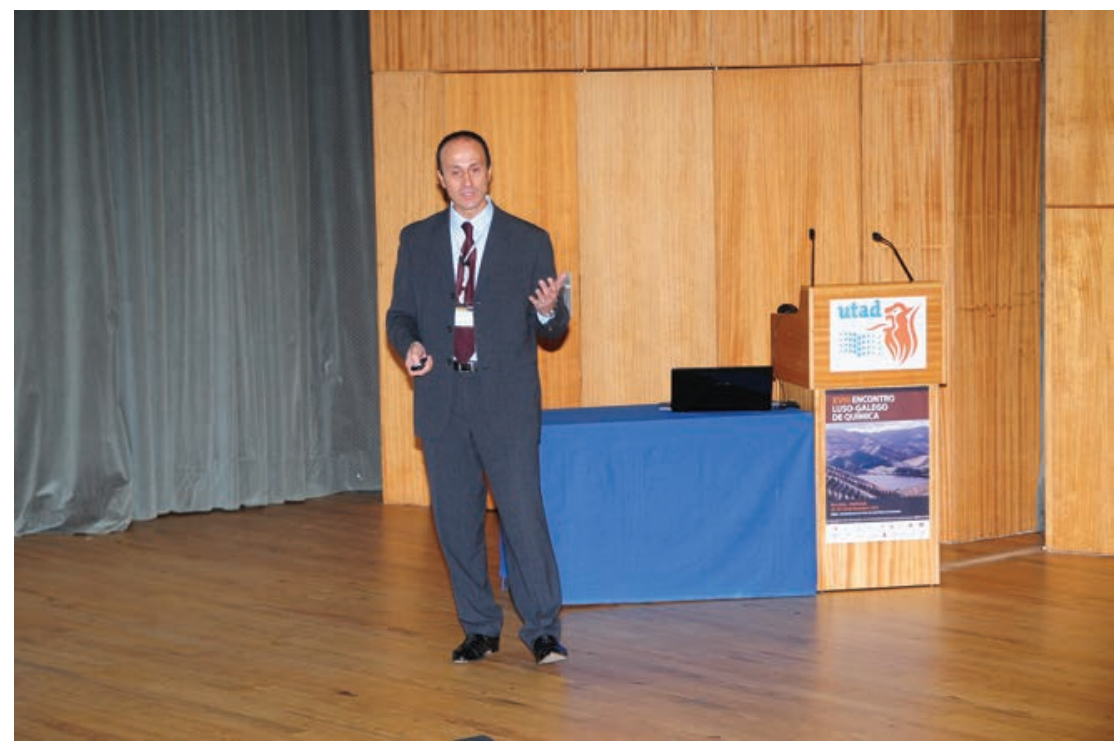

Lição plenária de Gianluca Li Puma (Universidade de Loughborough, Inglaterra)

no átrio da Aula Magna, patente ao longo dos 3 dias do Encontro.

No próximo ano a organização do XIX Encontro Luso-Galego de Química estará a cargo do Colégio Oficial de
Químicos da Galiza e será realizado em Vigo, em novembro de 2013.
José Alcides Peres (jperes@utad.pt) Comissão Organizadora

\section{3. ${ }^{\circ}$ Encontro Nacional de Química Terapêutica}

Nos dias 28 a 30 de novembro de 2012 teve lugar, na Universidade de Aveiro, o 3. ${ }^{\circ}$ Encontro Nacional de Química Terapêutica (3. ${ }^{\circ}$ ENQT). Tal como nos dois encontros anteriores (Porto e Coimbra), este congresso proporcionou aos seus participantes a possibilidade de apresentar e discutir os avanços mais recentes e as perspetivas futuras na descoberta e desenvolvimento de fármacos, com enfase especial nas interfaces entre Química, Biologia, Bioquímica Estrutural e Computacional e Medicina.

Os primeiros dois dias contaram com 4 lições plenárias proferidas por cientistas de renome mundial na Quími- ca Terapêutica, vindos da academia e da indústria, 6 lições convidadas e 18 comunicações orais proferidas por investigadores de diversos centros portugueses onde se desenvolve Química Terapêutica e também por investigadores portugueses no estrangeiro. Este encontro incluiu no seu terceiro dia o 1. ${ }^{\circ}$ Simpósio Luso-Espano-Bra- 